\title{
O PARADIGMA DO DESIGN DO LIVRO “INVISÍVEL”
}

lara Pierro de Camargo

Faculdades Integradas Rio Branco

iara.camargo@riobrancofac.edu.br

Resumo: Este artigo busca traçar um panorama e compreender o paradigma do design do livro "invisível", que pode ser entendido como o ideal de projeto do livro simples, neutro e tradicional. O termo "invisível" começou a circular nos campos do design editorial e da tipografia na década de 1930, após a palestra de Beatrice Warde intitulada Printing should be invisible. Esse conceito é compartilhado por vários autores e tipógrafos do período, como Stanley Morison e Eric Gill, embora utilizando outros termos. Alguns desses ideais foram posteriormente discutidos nas últimas décadas, por autores e designers como Richard Hendel, David Jury e outros que trabalham a partir dessa linha de pensamento.

Palavras-chave: Design de livros, tipografia, invisibilidade 


\section{INTRODUÇÃO}

Há hoje duas abordagens de design de livro que resultam em dois tipos de tratamento, como observa Hendel:

Existem duas abordagens filosóficas ao design de livros: há os que acreditam que o design deva ser neutro e atemporal e outros que ele deva refletir o conteúdo de uma forma mais óbvia (usando tipografia ou elementos de design relevantes relativos ao tema do livro). (HENDEL, 2013: 7)

A abordagem que, segundo Hendel (2013: 7), corresponde à ideologia de design que pressupõe resultados em certa medida neutros e atemporais costuma-se chamar "de 'taça de cristal' a partir do ensaio de Beatrice Warde":

Warde não estava sozinha em sua postura, que defende que o projeto para livros deve ser diferente de outros tipos de design gráfico. De forma diferente que a de outros designers gráficos, aqueles que projetam livros precisam estar cientes das convenções de como as pessoas leem. (HENDEL, 2013: 7)

O princípio da invisibilidade acabou se disseminando e foi usado de forma extensiva para explicar abordagens de design de outros períodos, não se restringindo apenas ao campo editorial, como é o caso de Gruszynsky (2008), que analisou a ideologia da tipografia modernista e do Estilo Internacional. Na época em que foi utilizado pela primeira vez (1930), no entanto, o termo foi defendido por Beatrice Warde como uma abordagem para a composição do texto de páginas de livros em prosa.

Por ser um conceito importante para a discussão de projetos em design editorial, torna-se necessário aprofundar a discussão e buscar entender os princípios que o norteiam.

Os primeiros livros impressos eram decorados e tinham uma configuração parecida com a dos manuscritos produzidos antes do advento da prensa com tipos móveis. Mesmo impressos, ganhavam acabamentos manuais, como capitulares e ilustrações. Após algumas décadas, na virada do século XV para o XVI, surge em Veneza, a partir dos livros portáteis criados na oficina de Aldo Manuzio, uma nova abordagem mais simples e com poucos ornamentos, que provavelmente reflete um interesse funcional, de ampliar a produção e reduzir os custos. Sabe-se que o design dos livros impressos por Manuzio influenciou a produção de obras na França e em outros países do continente europeu. Jan Middendorp (2012:22) acredita que "um livro como De Aetna, do cardeal Pietro Bembo, impresso na oficina de Aldus em 149596, não é significativamente diferente das brochuras produzidas hoje". Ou seja, o livro simples não é uma invenção nova, já que as primeiras tentativas de trabalhar a página impressa sem ornamentação são daquela época. Febvre e Martin (1992: 173-181) apresentam uma série de exemplos sobre custos materiais e de impressão e concluem que o papel é o elemento mais caro para a produção do livro entre os séculos XV e XVIII. A partir desse levantamento, pode-se entender que a produção de livros mais simples e portáteis tenha como interesse a economia dessa matéria-prima.

Entre os séculos XVI e XVIII, tanto livros simples quanto os ornamentados foram produzidos, porém a simplicidade parece ter começado a se tornar um estilo a partir dos livros impressos por John Baskerville e Giambattista Bodoni. 
A ausência de ornamentos e a página apenas tipográfica de Baskerville, segundo Adrian Wilson (1993: 20), "foi uma revelação no design de livros". Para Bartram (2004: 16), desde os primeiros impressores italianos, Baskerville foi o primeiro a praticamente dispensar a decoração em seus livros e Bodoni "completou essa revolução trazendo lógica ao arranjo dos títulos correntes".

No decorrer do século XIX, a partir da Revolução Industrial e de novas tecnologias de produção de papel (de qualidade inferior), de prensas a vapor e com o surgimento de máquinas de composição tipográficas mecânicas, a oferta e a demanda de livros impressos aumentou e, por conseguinte, sua qualidade diminuiu.

Como crítica ao livro "industrializado", surgem no final do século XIX pequenas casas publicadoras como a Kelmscott Press, de William Morris, empenhadas em produzir livros de qualidade, resgatando a tradição e a produção artesanal. Essa abordagem que se originou na Europa, mas também teve seguidores nos Estados Unidos, denomina-se Movimento da Imprensa Particular (Private Presses Movement). Livros como os da Kelmscott Press e os de outras prensas eram muitas vezes decorados e mostram uma visão mais estética que funcional, porém esse movimento, ao criticar e resgatar meios de produzir livros, estimulou o surgimento da "Reforma da Impressão ${ }^{1 "}$, no qual seus integrantes procuraram discutir e aprimorar as novas técnicas de impressão em busca de um livro bem feito, porém produzido industrialmente, já que aqueles produzidos pelas prensas particulares eram, na maioria das vezes, impressos em pequenas tiragens e para um público específico.

Kinross (2004: 64) explica que o "Movimento de Reforma da Impressão", que começou a se formar na Inglaterra logo após a Primeira Guerra Mundial, relaciona-se à Kelmscott Press, de Morris, pelo interesse de um resgate histórico e pela busca de padrões mais elevados. Os reformadores aceitavam, no entanto, a mecanização da composição tipográfica por meio de máquinas de composição como a Monotipo e a Linotipo.

A Reforma da Impressão parece ter demonstrado pelo menos dois interesses: o de produzir faces tipográficas adequadas a este novo maquinário e a de promover diretrizes para a boa composição. Kinross explica que uma das ideologias da reforma da impressão, quando se tratava do design de livros, era a de procurar aperfeiçoar a qualidade dos impressos utilizando máquinas de composição como a Monotipo, já que a tipografia dessas máquinas nas primeiras décadas do século $X X$, ao que parece, precisava ser aprimorada. Segundo Kinross, a relação dos reformadores à indústria se deu pela necessidade do desenvolvimento de tipos que se adequassem a ela e mostra que empresas líderes na produção de máquinas de composição nos Estados Unidos e na Inglaterra, bem como alguns fundidores de tipos para composição manual, passaram a produzir tipos baseados em modelos históricos, além de encomendar "designs" originais. (KINROSS, 2004: 70)

Talvez esse resgate histórico não apenas tenha proporcionado o desenvolvimento de boa tipografia para texto para ser usada em máquinas compositoras, mas pode ter estimulado uma abordagem mais simples de composição, a partir da divulgação dos trabalhos de impressores precursores que trabalhavam com páginas sem ornamentação. Sabe-se que especialmente os livros renascentistas italianos, como os produzidos por Aldo Manuzio, são frequentemente elogiados por

\footnotetext{
${ }^{1}$ Reform of Printing Movement. Termo utilizado por Kinross, 2004.
} 
tipógrafos e autores do início do século $X X$ que tornaram esse período altamente intelectualizado ao produzirem periódicos e livros sobre a história da impressão e da tipografia. Como exemplo, pode-se citar o famoso Printing Types (1922), de Daniel Berkeley Updike, que teve importante papel na revitalização da tipografia. Updike defendia o livro "simples" como se pode observar no ensaio Style in the Use of Type, de 1902, no qual apresenta as virtudes do livro "simples", bem executado, do final do século XV e início do XVI. Para Updike, os livros mais belos são aqueles sem elementos decorativos:

Outra qualidade que cria um estilo é a simplicidade; e aqui novamente os livros italianos têm muito a nos ensinar. Eles eram estritamente simples, dependendo apenas de belos tipos, de bom papel e de uma página proporcionalmente composta, que produzia um resultado elegante. Qualquer um pode colocar uma capitular decorada vermelha em cima de uma página para deslumbrar o leitor momentaneamente. Mas para produzir uma página agradável e bela apenas a partir de margens proporcionais, tipografia etc. requer muito estudo, experiência e gosto. Parece, portanto, que alguns dos mais belos livros são aqueles sem decoração. Estilo não depende de decoração, depende muito mais da proporção e da simplicidade. (Updike in PETERSON, 2002: 24)

\section{O IDEAL DO LIVRO “INVISÍVEL"}

O resgate histórico teve um importante papel de ampliar e aprimorar os tipos para impressão e naturalmente pode ter influenciado a redação de textos para promover princípios da boa composição e de como fazer bom uso de todos os recursos disponíveis, especialmente em periódicos como The Fleuron e The Monotype Recorder ${ }^{2}$, no qual grandes tipógrafos e designers como Oliver Simon, Francis Meynel, Beatrice Warde, Joseph Thorp e Stanley Morison colaboraram.

Segundo Moran (1917: 24), o movimento por uma tipografia mais simples no início do século XX foi iniciado pelo americano Theodore Low De Vinne (1828-1914), que publicou em 1904 um extenso manual em quatro volumes chamado Practical Typography. Pode-se comprovar a defesa do livro simples por De Vinne na passagem abaixo:

No livro comum, evite decoração e tipos esquisitos que não tornam o conteúdo claro, que não fazem o objeto mais claro. As grandes obras-primas da impressão são as mais simples. Tipos simples corretamente compostos e espaçados e com grande atenção aos pequenos detalhes, claramente impressos em tinta preta sobre papel liso e com margens apropriadas, têm um charme que é reconhecido por um inexperiente. Ele pode não saber por que, porém esse livro é mais agradável e atraente do que o livro profusamente decorado, mas ele vai perceber que livros assim destacam-se como obras superiores. (DE VINNE, 1904: 168)

Aqui se expõe não apenas a sua contribuição na defesa de um livro mais simples e funcional, que de acordo com Moran (1917: 24) o conjunto destes quatro

2 Stanley Morison contribuiu em The Imprint e foi editor de Monotype Recorder e The Fleuron. Beatrice Warde escreveu tanto para The Fleuron como Monotype Recorder, às vezes sob o pseudônimo de Paul Beaujon, além de depois se tornar editora deste último. 
volumes de princípios parecem ter inspirado Stanley Morison em seu famoso ensaio First Principles of Typography, abordado mais adiante.

O termo invisível foi utilizado pela primeira vez relacionado à tipografia de livros por Beatrice Warde. Não há evidência de que outros autores tenham utilizado esse termo antes dela, apesar de existirem outros para designar ideias semelhantes, como "simplicidade" e "clareza", por exemplo.

Muitas das ideias de autores, tipógrafos e impressores do período parecem convergir, e assim há aparentemente um intercâmbio entre elas, especialmente entre tipógrafos americanos e ingleses, sobretudo durante as décadas de 1920 e 1930.

No início dos anos 1920, a americana Beatrice Warde começou sua carreira como bibliotecária da American Type Founders ${ }^{3}$ (ATF) e era casada com o eminente tipógrafo e designer de livros Frederic Warde que, em 1924, foi chamado para trabalhar na Inglaterra para a Monotype Corporation a convite de Stanley Morison. É possível que a experiência anterior de Warde em uma biblioteca cujo acervo era especializado em tipografia tenha lhe dado repertório suficiente para escrever um artigo para o periódico The Monotype Recorder, que tinha Morison como editor.

Sob o pseudônimo de Paul Beaujon, Warde escreveu em The Fleuron $n^{\circ}$ 6, de 1928, sobre a ornamentação de livros nos Estados Unidos. Nesse artigo, Warde utiliza a ideia de transparência, depois retomada no famoso discurso de 1930, intitulado Printing should be invisible e proferido em um jantar para a Guilda dos Tipógrafos Britânicos. Em Printing should be invisible Warde (1956: 11-12) faz uma analogia entre a tipografia de livros (página impressa) e uma taça de cristal, estabelece um paralelo entre a taça e sua função de recipiente transparente para que se veja o conteúdo. Segundo Warde (1956: 11), a taça possui uma haste cuja função é a de ser segurada, para que se evite que impressões digitais sejam marcadas na copa, onde o vinho é colocado. Ou seja, para evitar a criação de ruídos (interferências) no recipiente que alterem a visão do líquido. Essa haste é comparada às margens do livro, cuja função é evitar que os dedos do leitor se apoiem sobre o texto. Para a autora, taças de vinho e a composição tipográfica em livros devem ser ambas transparentes.

Warde continua com a comparação entre a taça e a página impressa, agora ao tratar de outros dispositivos compositivos, como o uso essencial da entrelinha que evita a duplicação ${ }^{4}$. Talvez também esteja implícita a relação com o tamanho do tipo e a largura da coluna: "E há maneiras de compor linhas que, embora de aparência bem razoável, deixam o leitor subconscientemente preocupado, temendo duplicar as linhas, ou ler três palavras como se fossem uma, e assim por diante" (WARDE in ARMSTRONG, 2015: 48-49).

Warde compara uma composição "mal feita" a discursos com ruídos. Nesse sentido, "os tipos bem empregados são invisíveis enquanto tipos, assim como a voz ideal é o veículo despercebido para a difusão de palavras e ideias". (WARDE in ARMSTRONG, 2015: 50). Fica claro aqui também que ela trata da composição dos tipos e não do desenho dos tipos em si, ou seja, parece tratar de uma abordadem de design funcionalista e "invisível", que aparentemente também é defendida por outros tipógrafos, como ela sugere na passagem abaixo:

\footnotetext{
3 Importante distribuidora e produtora de tipos de metal fundidos.

4 Do original em inglês doubling. Termo usado para o problema que ocorre quando o leitor pula uma linha indevidamente ou lê repetidamente a mesma linha.
} 
(...) essa ideia do impresso como meio de transmissão é, pelo menos na opinião de todos os grandes tipógrafos com que tive o privilégio de conversar, o único indício que nos serve de orientação através do labirinto. Sem essa humildade essencial de espírito, já vi designers fervorosos equivocarem-se de maneira irremediável, cometerem os erros mais absurdos por causa do entusiamo excessivo, muito mais do que eu teria considerado possível. (WARDE in ARMSTRONG, 2015: 50-51)

Para reforçar sua posição sobre a transparência da página impressa, ela afirma que "quanto aos livros, a tarefa do tipógrafo é colocar uma janela entre o leitor dentro de um aposento e a paisagem, que são as palavras do autor" (WARDE in ARMSTRONG. 2015: 53), então compara abordagens de design com três tipos de janela (vitral, janela transparente e janela com o vidro fragmentado).

Warde (in ARMSTRONG, 2015: 53) conclui a discussão sobre as janelas explicando que qualquer desvio ou ruído pode ser problemático e finaliza o ensaio defendendo a "invisibilidade" da composição tipográfica, ou seja, do design das páginas (miolo) de um livro.

Robin Kinross (2004: 80) acredita que este texto de Warde "recapitula a doutrina morisoniana de abnegação e obediência em termos de um discurso de um jantar", ou seja, talvez critique o discurso como superficial e acredite que este texto demonstra influências das ideias de Stanley Morison, com quem Warde trabalhou e sempre conviveu.

Nesse contexto, é difícil defender de quem é a ideia original, já que tanto Warde quanto Morison foram influenciados por outras fontes e conviviam com tipógrafos defensores de ideias semelhantes. Sabe-se, por exemplo, a partir de McLean (1995: 17), que Warde foi extremamente inspirada pelo livro de Joseph Thorp Printing for Business, de 1919, que valoriza a página simples e condena o excesso de decoração, como se pode verificar no trecho abaixo extraído desse livro:

A respeito de tipos e composição de tipos, o primeiro desiderato é a legibilidade. A decoração é puramente subsidiária e decoração que põe em risco a legibilidade é resultado de trabalho mal feito. Isso nos leva a pensar não apenas na escolha certa do tipo, mas no entendimento correto de alguns princípios relativos à sua disposição. (...) a simplicidade, a dignidade e um senso de estilo são suficientes para se ler uma mensagem mais rapidamente e trazem mais prazer do que um trabalho espalhafatoso e excessivamente ornamentado. (THORP, 1919: 49)

Warde parecia empenhada em promover um livro "invisível" e de qualidade, o que se reflete na redação de diversos outros artigos. É importante também entender que, talvez por seu papel como funcionária da empresa Monotype, Warde tinha que apresentar propostas e soluções de design, o que, de certa forma, também deveria valorizar a companhia aos olhos do público, manisfestar um compromentimento com a qualidade e promover didaticamente a impressão e produção de livros de qualidade.

Apesar de defender a "invisibilidade", Warde não faz críticas nem elogios a livros específicos e, por isso, é difícil inferir em que medida a página é invisível ou não. No artigo On the choice of type faces, escrito por ela sob o pseudônimo Paul Beaujon para o periódico The Monotype Recorder, ela escreve que tipos (fontes) distintos dão 
tons diversos ao texto, da mesma forma que há diferença quando mais de uma pessoa (vozes diferentes) pronuncia um mesmo discurso:

Componha uma página em Fournier comparando a outra em Caslon e uma terceira em Plantin, é como se você estivesse ouvindo três pessoas diferentes proferindo o mesmo discurso - cada uma com pronúncia impecável e clareza, mas por meio de uma personalidade diferente. Talvez o leigo não seja capaz de diferenciar uma composição "old style" a partir de outras duas do mesmo grupo, no entanto ele não poderia ler as três páginas sem ao menos inconscientemente discerni-las. A menor variação da construção de uma serifa é enorme e pode ser comparada a uma vibração de um disco de metal, num receptor de telefone que vibra e reproduz sons apresentados por uma ou por outra voz, e mesmo assim é fácil deduzir por essas vibrações que um velho amigo está nos perguntando: “Adivinha quem é?" (BEAUJON, 1933: 6)

A partir do exposto acima, qualquer variação do design de tipos pode dar ao texto "uma voz", certa "personalidade", e o ideal da invisibilidade proposto por Warde torna-se um pouco escorregadio. Fontes como Fournier, Caslon e Plantin, apresentadas no trecho acima, por seu amplo uso, podem ser consideradas bem feitas e adequadas para a composição de textos, porém todas têm "personalidades" distintas.

Há, então, certa contradição sobre o ideal da "invisibilidade" nos discursos de Warde, uma vez que ela considera que variações tipográficas dão um "tom" diverso ao texto impresso, já que mesmo pequenas diferenças entre tipos de mesma classe podem, ainda que inconscientemente, causar impressões diversas para o leigo.

Em ensaio escrito no início da década de 1950, The Design of Books ${ }^{5}$, publicado na coletânea Crystal Goblet: sixteen essays on tipography (1956), Beatrice Warde condena o descaso modernista com a história e defende que o livro deve ter uma aparência familiar, própria do design de livros e não de qualquer outro material impresso. (WARDE, 1956: 32-33). A autora (1956: 36) apresenta outras questões sobre o design de página, como a importância das margens, e o uso, para ela problemático, de elementos decorativos que podem comprometer o design. Nesse contexto, 0 profissional que se vale de muitos recursos visuais pode comprometer a primeira função do objeto, a leitura, para valorizar sua expressão pessoal.

Mesmo algumas décadas depois da escrita de Printing Should be Invisible, em entrevista realizada na Austrália, em 1959, e transcrita por Sara De Bondt (2012) ${ }^{6}$, Warde ainda promovia esse ideal, o que mostra seu desejo de preservar a "invisibilidade".

Apesar de Warde ter proposto o termo invisibilidade, especialmente relacionado a obras em prosa (textos para leitura contínua, como romances), não se pode deixar de discutir e avaliar os ideais de tipógrafos de seu convívio na época.

Stanley Morison, que, como se sabe, trabalhou diretamente com Warde, também defende a "invisibilidade", embora sem utilizar esse termo, no ensaio First Principles of Typography, publicado originalmente em 1930 na sétima e última edição do periódico The Fleuron e posteriormente republicado em livro, em 1936. Morison

5 Publicado na coletânea The Crystal Goblet. Texto de 1951" Paper for the Weekend Conference of the Library Association."

6 Disponível em: <http://www.eyemagazine.com/feature/article/beatrice-warde-manners-and-type>; acesso em setembro de 2015. 
propõe um conjunto de diretrizes de composição que devem ser utilizadas quanto à construção da mancha de texto, das margens, dos espaçamentos, da escolha de tipos etc., adverte que a tipografia é um meio "essencialmente utilitário" e apenas "acidentalmente estético" e que

(...) qualquer disposição de material impresso, independente de sua intenção, se tiver o efeito de interferência entre o autor e o leitor está errado (...) livros impressos são feitos para serem lidos e aqui resta pouco espaço para uma tipografia "brilhante", ou seja, expressiva ou "inspirada". (MORISON, 1936: 1)

A fluência da leitura é uma das maiores preocupações de Morison, que explica que mesmo o olhar de um leitor experiente tem dificuldade para ler textos com uma quantidade acima da ideal de palavras por linha. (MORISON, 1936: 9)

O autor apresenta detalhadamente os princípios da boa tipografia para livros, mas que podem ser resumidos no seguinte parágrafo:

De acordo com a nossa doutrina, um livro bem construído é feito a partir de páginas verticais oblongas com a disposição de parágrafos que tenham uma média de 10 a 12 palavras por linha e consistentemente espaçados, compostos com uma fonte tipográfica de tamanho confortável e aparência familiar; as linhas devem ser suficientemente separadas para evitar duplicação." (MORISON, 1936: 16)

Morison era favorável à produção padronizada de livros, como se pode observar a partir de Nicolas Barker (Barker, 1972: 219), em ocasião na qual Morison procurou convencer o responsável pela produção dos livros da Doubleday nos Estados Unidos, Daniel Longwell, a padronizar o design. Outra referência que aponta seu gosto pela padronização é encontrada em McLean (1975: 97), que explica que Morison padronizou a tipografia (Baskerville) e o leiaute para os romances publicados pelo editor inglês Victor Gollancz nos anos 1930.

O tipógrafo inglês Eric Gill, amigo próximo de Morison e Warde, em An Essay on Typography, de 1931, apresenta ideais próximos aos deles:

O livro é um objeto para ser lido - todos nós devemos começar a partir disso e vamos supor que o leitor é uma pessoa sensível e sensata. Agora, a primeira coisa que deve ser notada é que é o ato de ler e as circunstâncias desse ato é que devem determinar o tamanho do livro e o tipo da tipografia a ser usada. (...) Um bom tipo é apropriado para todo e qualquer livro, e o tamanho de um livro é regulado não pelo que ele contém, mas pelo modo pelo qual ele será lido, se o livro será lido segurado pelas mãos (como um romance), lido apoiado em uma mesa (por exemplo, livros de história ou referência com mapas ou outros necessariamente com grandes ilustrações) ou em uma mesa ou estante (como um missal ou um livro de coro), ou mantidos no bolso (por exemplo, um livro de oração ou um dicionário). (GILL, 1988: 105)

O design do livro, para Gill (1998: 108), "deve ser governado pelas mãos e pelos olhos", ou seja, deve se adequar a questões anatômicas do manuseio e da visão. Gill observa também que linhas de texto compostas com mais de 10 a 12 palavras são difíceis 
de ler, já que linhas longas aumentam a atividade muscular dos olhos e, às vezes, da cabeça. Desse modo, linhas de texto longas necessitam de entrelinhas maiores.

A partir das ideias dos autores acima, a invisibilidade pode ser entendida como um preceito funcional, na medida em que "livros são feitos para serem lidos". É importante notar, no entanto, que o ideal da "invisibilidade" não se refere apenas à "simplicidade" da página, mas a um conjunto de regras de composição e estilo que podem ser encontradas em textos como os de Morison e Gill. Warde (1956: 13) apresenta as diferenças entre readability (fluência de leitura) e legibility (legibilidade): mesmo uma página sendo legível, não é necessariamente readable. A fluência de leitura está relacionada à facilidade de se ler um texto. Infere-se que a "fluência da leitura" relaciona-se aos princípios da invisibilidade: livros bem compostos, com uma quantidade ideal de palavras por linha e espaços interlineares e margens satisfatórios. A simplicidade da página impressa, como vimos, foi também defendida antes de Warde e Morison por DeVinne, Updike e Thorp e, do ponto de vista desses autores, esse ideal da página simples e sem ornamentos pode ser entendido como princípio estético além do funcional, o da leitura.

No entanto, a partir de Morison, pode-se inferir que a simplicidade, a "invisibilidade" pode ter aberto o caminho para a padronização, pois se os livros são simples e não chamam a atenção para seu design podem ser padronizados, o que torna sua produção mais rápida e barata.

\section{A "RETOMADA" DA INVISIBILIDADE}

Nas últimas décadas do século XX e nas duas primeiras do século XXI, posições como as de Beatrice Warde ainda sobrevivem, a partir de discussões de autores como Hendel, Jury e Lee, que se justificam por um cuidado com a produção de livros a partir de novas tecnologias (editoração eletrônica e tipografia digital) e processos editoriais.

Em O design do livro, Richard Hendel (2006) apresenta a invisibilidade não apenas como uma abordagem de design, mas como fenômeno que se observa a partir da relação do público leitor com o projeto gráfico: "Quando aceitamos a ideia de que o importante no livro é o significado das palavras e não o modo como elas se apresentam, isso se deve à própria invisibilidade do design". (HENDEL, 2006: 1) Ele explica que o design é invisível à medida que não foge do padrão, ou seja, quando é convencional e não "chama a atenção" (HENDEL, 2006: 9).

David Jury (2007: 31) acredita que em livros "o melhor design era o invisível" e constata que hoje há mais liberdade, tecnologias e materiais disponíveis, porém, algumas investigações criativas, que testam limites físicos dos livros, nem sempre são "nobres", como a "tipografia discreta" (JURY, 2007: 17).

Marshal Lee (2004: 109) explica que, em tipografia, é necessário "reconciliar as demandas estéticas e práticas de seu tempo". O autor exemplifica que com a tipografia em metal era possível, para o compositor, produzir quase tudo que o designer especificava, mesmo que isso fosse impraticável e caro. Assim, o designer evitava, por razões econômicas, projetar livros complexos. Desse modo, os limites práticos de certa forma impuseram um "rigor estético". Hoje, porém, não há restrições na composição digital, ou seja, essse rigor não é mais condicionado às ferramentas. Lee assinala: 
Anteriormente, tipógrafos eram guiados pelos melhores exemplos de trabalhos feitos por seus antecessores e pelas tradições do ofício. Apesar de esse processo ter resultado em repetições sem criatividade, forneceu um quadro no qual os designers de todos os níveis de competência produziam um excelente trabalho. (LEE, 2004: 109)

No trecho acima, o autor recomenda que sejam observados bons exemplos de livros já publicados, da mesma forma que Morison e Updike, por exemplo, foram inspirados pelos livros Italianos dos séculos XV e XVI. Bons exemplos, mesmo simples, são na maioria das vezes "bem feitos" por seguirem algumas regras. Jury acredita que regras restringem os erros, e Lee (2004: 109) avalia que hoje, com a composição tipográfica digital, muitas tradições tipográficas podem ter perdido sua influência.

Hendel (2006: 9) reitera a importância das convenções e tradições:

A tipografia de livros apoia-se (alguns poderiam dizer: mergulha) na tradição e nas convenções. Os designers devem entender a história e as convenções da tipografia de livros, porque há boas razões para a sua existência. Mais de meio século atrás, Stanley Morison e Oliver Simon reiteraram o que devemos considerar os princípios da boa tipografia. Essas supostas regras para um bom design de livros não são absolutas, mas fornecem pontos de partida úteis.

É preciso observar também as condições atuais em que os livros são publicados: grandes grupos editoriais talvez tenham mais interesse no lucro do que na qualidade do design. Dessa maneira, ideais do livro "bem feito" precisam ser retomados.

Chappel e Bringhurst (1999: 295) apontam que hoje, com a engenharia de softwares, a composição tipográfica está à disposição de qualquer um e "a liberdade de publicar é quase absoluta". No entanto, os autores advertem que há grandes empresas que monopolizam o mercado e muitas vezes não são necessariamente editoras, mas visam ao lucro, mais do que à divulgação de textos impressos. Apresentam, assim, as diferenças entre um editor e um gestor (que hoje é quem administra, em geral, as grandes editoras):

Os objetivos de um editor são, via de regra, contribuir para a cultura através da publicação de bons livros e desfrutar os prazeres de uma vida literária e, também, fazer um pouco de dinheiro no processo. Os objetivos do gestor, via de regra, são a máxima penetração no mercado, cota máxima de mercado, e lucro máximo. (CHAPPEL e BRINGHURST, 1999: 295)

É importante ressaltar que o modo de produção do livro se alterou substancialmente após o lançamento do computador pessoal, que permitiu aos designers manipular tanto o processo quanto o projeto (sabe-se que em especial antes a divisão de trabalho do designer do livro e do tipógrafo se intensificou e nem sempre era o próprio designer que executava o processo). Ao manipular processo e projeto, 0 designer podia também "manipular" a tipografia (trabalho antes restrito ao impressorcompositor). Além disso, a tipografia em metal era "inflexível". Se antes o trabalho tipográfico apresentava diversas restrições técnicas e métricas, sendo, conforme Jury (2007: 14-15), inflexíveis, o computador torna a tipografia flexível. 
Hoje os softwares de editoração eletrônica oferecem muita maleabilidade e flexibilidade ao design que possibilita composições menos rígidas, mas que, ao mesmo tempo, pode ser um recurso perigoso aos que, intencionalmente ou não, distorcem a forma dos tipos ou usam margens mínimas. ${ }^{7}$

Jury (2007: 16) assinala que:

Atualmente, muitos tipógrafos estudaram em escolas de arte e de design foram incentivados a ser mais flexíveis na linguagem que empregam, bem como a reconhecer que as reações emotivas têm uma função e que os textos podem ser concebidos com paixão. A tecnologia desempenhou um papel importante nesta transformação, tornando o processo tipográfico mais insular, proporcionando independência e a oportunidade de experimentar.

O autor acrescenta também que, apesar da flexibilidade de hoje, muitas regras e convenções permanecem e devem ser consideradas. (JURY, 2007: 17)

Soma-se à questão dos novos meios de produção, como apresenta Hendel, a questão da padronização e da baixa qualidade de muitos livros:

Como podemos saber algum dia qual é o impacto que tem um design sobre a edição? Peguem os best-sellers nas livrarias e examinem seus designs. É tão raro você achar um bom que chega a desanimar. Os livros que mais vendem são, na maioria das vezes, aqueles cujas páginas são destituídas de margens e carregadas de uma tipografia repulsiva. (Hendel, 2006: 25)

A questão da invisibilidade hoje pode carregar duas ideias: a de que o leitor não presta atenção no design, porque é tão comum e tradicional; ou pode também conotar a qualidade do projeto, como se extrai a partir de Lupton (2006: 63): "uma das funções mais refinadas do design é de fato ajudar os leitores a não precisar ler. ${ }^{8 \text { " }}$ (LUPTON, 2006: 63), ou seja, o design tem o papel de facilitar a leitura. Muitas vezes o leitor pode prestar atenção no design de um livro, ou seja, percebê-lo, especialmente se é mal feito, se a leitura é incômoda.

\section{CONCLUSÃO}

Com base neste breve panorama, é possível perceber que o ideal do livro "invisível" não se restringe a uma preocupação do início do século XX. Antes de parecer um design simples, o ideal do livro invisível é um valor estético embasado em princípios de produção.

É importante ressaltar que os textos aqui discutidos, apesar de defenderem o design de um livro simples, não propõem o "simplório", representam um conjunto de práticas que devem ser seguidas para projetar um livro "bem feito". Mesmo que os ideais de Morison e Warde pareçam alinhados à indústria editorial (de um livro simples e tradicional), a "invisibilidade" e a ausência de ornamentos promovidas por eles não

7 Em composição com tipos móveis as margens tinham que ser maiores por conta da imposição das páginas, hoje é possível utilizar margens muito pequenas, o que pode ser problemático, uma vez que a largura das margens, como já tratou Beatrice Warde, devem permitir que o leitor segure o livro sem que os dedos fiquem sobre o texto.

8 Itálico do original 
correspondem apenas a um livro de texto corrido comum, mas baseado em princípios funcionais. Infere-se que esta ideologia busca favorecer o leitor, não apenas o lucro do editor.

É possível perceber que as atitudes de Hendel, Jury e Lee resgatam, de certa forma, os princípios da invisibilidade de outrora para refletir sobre os problemas editoriais atuais e, dessa maneira, com o resgate de algumas regras (não mencionadas aqui, mas apresentadas em seus textos), alertam para a importância da produção de livros de qualidade, já que em muitos livros impressos alguns princípios e convenções são neglicenciados.

\section{REFERÊNCIAS}

ARMSTRONG, Helen (org.). Teoria do design gráfico. Tradução de Cláudio Marcondes. São Paulo: Cosac Naify, 2015.

BARKER, Nicolas. Stanley Morison. Cambridge: Harvard University Press, 1972.

BARTRAM, Alan. Bauhaus, Modernism and the Illustrated Book. New Haven: Yale University Press, 2004.

BEAUJON, Paul (Beatrice Warde). On the Choice of Typefaces. London, Monotype recorder, volume XXXII: 1933. P. 5-11

. (Beatrice Warde) On Decorative Printing in America. The Fleuron: A

journal of Typography n. 6. Cambridge, At the University Press AND New York, Doubleday Doran \& CO. 1928. (p. 69-93)

BONDT, Sara de. Beatrice Warde: Manners and Type. Eye no. 84 vol. 21, 2012. Disponível em: http://www.eyemagazine.com/feature/article/beatrice-wardemanners-and-type. Acesso em setembro de 2015.

CHAPPELL, Warren. BRINGHURST, Robert. A Short History of the Printed Word. Vancouver: Hartley \& Marks Publishers Inc., 1999.

DE VINNE, Theodore Low. The Practice of Typography: Modern Methods of Book Composition; A Treatise on Type-setting by Hand and by Machine and on the Proper Arrangement and Imposition of Pages. New York: The Century Co., De VInne Press, 1904.

FEBVRE, Lucien; MARTIN, Henry-Jean. 0 aparecimento do livro. São Paulo: Unesp, 1992.

GILL, Eric. An Essay on Typography. Jaffrey, New Hampshire: David R. Godine Publisher Inc., 1988.

GRUSZYNSKY, Ana Cláudia. Design gráfico: do invisível ao ilegível. Segunda edição. São Paulo: Rosari, 2008.

HENDEL, Richard. 2006. O design do Livro. São Paulo: Atelier Editorial.

Press, 2013.

Aspects of Contemporary Book Design. lowa City: University of lowa

JURY, David. O que é tipografia. Barcelona: Editorial Gustavo Gili, 2007.

KINROSS, Robin. Modern Typography. London: Hyphen Press, 2004. 
LEE, Marshal. Bookmaking: Editing, Design, Production. Third Edition. New York: W.W. Norton \& Company, 2004.

LUPTON, Ellen. Pensar com tipos. Tradução André Stolarski. São Paulo: Cosac Naify, 2006.

MCLEAN, Ruari. Modern Book Design: From William Morris to the present day. London: Faber \& Faber, 1958.

MIDDENDORP, Jan. Shaping Text. Amsterdam: Bis Publishers, 2012.

MORAN, James. Stanley Morison: His Typographic Achievement. London, Lund Humphries Publishers: 1971.

MORISON, Stanley. First Principles of Typography. New York: The Macmillan Company, 1936.

PETERSON, William S. 2002. The Well-Made Book: Essays \& Lectures by Daniel Berkeley Updike. New York: Mark Batty Publisher.

THORP, Joseph. Printing for Business: A Manual of Printing Practice in Non-technical Idiom. London, John Hogg: 1919.

WARDE, Beatrice. The Crystal Goblet: Sixteen Essays on Typography. Cleveland: World Publishing Company, 1956.

WILSON, Adrian. The Design of Books. San Francisco: Chronicle Books, 1993. 